\title{
Bringing Together Forms of Collective Engagement in Youth Transitions
}

\author{
Processes, Practices and Theoretical Perspectives
}

Valentina Cuzzocrea, Ben Gook and Bjørn Schiermer

Since the 1990s, individualisation theories have strongly influenced discussions about youth transitions. Faced with apprehending increased complexity, and how young people handle it, much scholarly research on transitions has thus depicted youth as 'sole travellers'. This insight holds some truth for lives lived in neoliberalised, financialised capitalist societies - and the resulting uncertainty that is widely felt and documented among people in such societies. Bauman was surely right to notice that 'uncertainty is a powerful individualising force' today (2001: 24). This issue is pronounced in studies of precarity, itself a dominant theme in understanding how young people today navigate uncertain pathways towards adulthood (Biggart and Walther 2006, Côté 2002). For Beck, individuals work to find 'biographic solutions to systemic contradictions' (1992: 137, see also Beck and Beck-Gernsheim 2002, Bauman 2001). Further, developments of the individualisation thesis have fuelled a debate on the priority of agency versus structure in the study of youth and beyond (see for instance Brannen and Nilsen 2002 and 2005). This debate also encompasses arguments related to a possible misreading of the work by Ulrich Beck (Woodman 2009 plus Woodman 2010, Roberts 2010, 2012 and Threadgold 2011). Individualisation has pertained to both the risk associated with transitions as well as managing the risks themselves (Kelly and Furlong 2005: 212). In the last resort, the individual bears the risks. As a result, policy goals can also be individualistic in that 'they place responsibility for seeking, gaining and maintaining employment on the individual' (McDonald et al 2020: 449).

However, we argue that there is more to this story. This set of approaches to individualisation, for all its necessity and acuity, is not conducive to engagement

1 This chapter is supported by the Open Access Publishing Fund of the University of Cagliari, with the funding of the Regione Autonoma della Sardegna - L.R. n. 7/2007. 
with concrete collectivity. In this collection, we complicate the individualisation scenario by paying attention to forms of collective engagement. The book adds up to the claim that young people, even if they are uncertain and anxious, are not as solitary as they appear in prevailing sociological accounts.

Youth transition research has lacked genuine interest in the multiplicity of concrete collective aspects of young people's lives. It has mostly highlighted, on a collective level, the reproduction of class divisions and class-based 'habitus' through the education system, and the labour market at an individual level (France and Roberts 2017). Scholars have typically focused on youth employment, reproduction mechanisms, and on structural transition problems in western societies - to convey a new portrait of increasingly messy and 'nonlinear' transitions. While the study of youth transitions can be used as a prism to make the harsh economic and political realities of contemporary (western) society visible and bring critical attention to the creation of a new young precariat, the intensity of the collective dimension related to being young and in transition, still cannot be ignored. We know too little about the collective articulation of this transition. The diachronic perspective, in particular, so crucial to transition studies, almost unavoidably carries a focus on the individual's trajectory, where the social soon becomes a negative 'structure', namely restriction and hindrance of (otherwise 'free') individuals. This collection challenges this view by recollectivizing transitions either by bringing to the attention of studies of youth transitions a series of conceptual frames peripheral in youth studies (for instance, 'assemblage'), or by reflecting on standard concepts in youth studies (such as class or employment), proposing to pursue them differently.

Recently, Colombo and Rebughini have focused on young people's lives as oriented to a 'politics of the present' based on the development of specific set of personal capacities. "The capability, and the need to manage complexity, plurality, uncertainty and variability,' they write, 'has become a mark of the experience of contemporary youth and may constitute a basic component in creating innovative forms of social relations' (Colombo and Rebughini 2019:4). Indeed, to unpack the tensions and strategies in this increasing complexity, studies have flourished across the globe that seek to understand how young people identify and enact possibilities to make their way towards adulthood (Leccardi 2009, Colombo et al 2018, Bertolini et al 2019, Spanò and Domecka 2020, Howie and Campbell 2017, Tejerina 2019, Threadgold 2018, Wyn et al 2017). It would be impossible to review all these studies in the limited space here. Nevertheless, the prevalent line of interpretation presents individualised ways of tackling risk and uncertainty. This is often coupled with recognising 
that uncertainty is unlikely to disappear from young people's lives in current conditions.

Symptomatically, the terminology used in existing transition research typically includes expressions such as 'navigation models', 'life-management', 'reflexive biographical projects', 'choice biographies', thus using an argot committed to describing individual choices. In this volume, we complicate the idea that young people's lives are solely centred on individualised journeys with biographical 'turning points' (Abbott 2001, Lyon and Crow 2012) or transitional 'critical moments' (Thomson et al 2002, Tomanović 2012). It is not by chance that this interstitial space is also a 'crossroad' (Bagnoli and Ketokivi 2009), albeit a meeting place where the subjective centrality of individuals' decisions has remained strangely unquestioned as to their interrelation with other people whom they might meet at this proverbial junction, or with whom they might have travelled there with in the first place. While a focus on individual choices has, among other advantages, the virtue of linking theoretical concerns with sensitive policy issues, the resulting body of work has been marked by a disinterest in the collective forms through which young people congregate, either in person or imaginatively.

In youth studies, a famous metaphor proposed by Furlong and Cartmel has - possibly unintentionally - conveyed and strengthened an individualistic assumption (2007, first ed. 1997). Furlong and Cartmel suggested that, before the spread of individualisation, young people would construct their paths as if they were travelling by public transportation: the direction taken was thus predictable and linear, like a train line or a bus route. In contemporary western societies, however, it seems like young people travel towards adulthood as if they are in private cars, perceiving that they are driving alone along various routes. Furlong and Cartmel termed this perception an 'epistemological fallacy' and warned against 'an overemphasis on the significance of individual reflexivity' (2007: 143). Following the decline of linear transitions towards adulthood, up-to-date accounts of youth transitions have further complicated private transportation as a good metaphor for contemporary transitions. This reassessment is due, in part, to structural conditions creating complex situations for young people. Consequently, to come back to the metaphor: private cars are basically out of reach for many young people; car sharing is the growing market sector (Magaraggia and Benasso 2019). Clearly, not only economic restrictions have changed the scenario, but also a broader cultural sensibility about navigating the transition itself and how young people make sense of it. This new moment makes space for questioning how young people 'travel together' through this uncertainty. 
We are not the first to contest the individualisation thesis. Voices have emerged against taking 'risk' and 'resilience' as central in understanding young people's individual lives (e.g., Foster and Spencer 2011). Social generation, a crucial 'collective' term in youth studies, has also often been taken as 'conceptually problematic' (Roberts and France 2021). In generational analysis, meanwhile, neither historical circumstances nor underpinning structural conditions are at the forefront of analysis (Nilsen and Brannen 2014, Nilsen 2021).

Looking at this set of issues from a different perspective, it is banal to say that interaction with others helps to form youth identities. The very intensity of being young has to do with 'being in transition' - that is, with all kinds of transformations, risks, insecurities, and essential choices young people are asked to make. However, we know little about the collective articulation of this collective entanglement in young people's lives, and how the actualities of this take shape.

The occasion to start this book project was the International Sociological Association Congress in Toronto in July 2018, where we were pleased to host two sessions on the theme of youth and collectivity within the work organised by the Research Committee 34 (Sociology of Youth). From the beginning, our approach has been very much exploratory; yet we attracted a good number of submissions and raised considerable interest in framing the transition to adulthood debate under this frame. This book gathers some of those contributions, but it broadens the focus to works outside the sociological realm: as much as the youth transitions field is not purely sociological but very much interdisciplinary, 'collective transitions' are such too.

We did not depart from a single theoretical rationale for approaching this theme. It is, in that sense, pluralistic. We were chiefly interested in establishing a framework that could bring various 'collective' narratives and experiences under a strengthened umbrella concept. We hoped this could answer important questions about youth experience today. In unveiling practices of innovation and routines through which phenomena of youth collectivity take shape in various contexts, we asked ourselves and the contributors: what are these circumstances? Along what lines have they developed? Drawing from the evidence, can we envisage ways to facilitate youth transitions via sustaining the forms of collective actions with which they engage? What are the strengths and limitations of this focus? We deliberately decided to concentrate on those aspects of young lives that, coming together in forms of collective engagement, 
become relevant for the transition to adulthood. Not only the more traditional 'transition' aspects such as those related to education and work are explored and discussed in this vein, but also other aspects, perhaps closer to youth subculture research, such as those related to the use of social media.

In sum, we are interested in exploring here how transitions happen collectively today. Beyond youth studies' productive focus on the individual in the past two decades, attention to forms of collective engagements can help us see the most current developments of these transitions. It is easy to imagine, for instance, the impact that the global financial crises might have played in this direction, or more recently, eco-conscious youth movements such as Fridays for Future, famously led by the young Swedish activist Greta Thunberg. Not to mention the re-articulation of forms of sociality likely to take place even after the COVID-19 pandemic, which is unfolding as we send this to print - and whose medium-term effects we cannot yet analyse.

Further, we consider this collection's global appeal as both necessary and unique. Not only because it covers forms of collective engagement in an array of youth subjectivities, but also because it engages with various methods and geographical localities, spanning Europe, Australia, Canada, and Asia. Further, contributors are based in different countries around the globe and have drawn on distinct research traditions. The authors seek to investigate how the contextual specificities interrelate with international perspectives.

However, the collection is globally pertinent in several ways. Not least it gives space to case studies in several regions outside the commonly studied western countries. Aspects of collective engagement change their meanings when seen outside/inside their locations. For instance, Michelle Mansfield's chapter on graffiti art practices in Indonesia reveals possible misunderstandings when western assumptions are adopted tout court. The surrounding conditions affect how young people manage their transitions to adulthood. The chapters are therefore strongly empirically substantiated to highlight these dynamics, making the case that forms of collectivity are broadly relevant among youth across continents, even as the conditions shift.

The second, more articulated level of this collection's global appeal relates to the changing meaning of forms of collectivity through the lens of various phenomena. Take social media use - while it is commonly assumed that young people have similar access to technology, such as social media, we must see their use in connection with the realities of their socio-economic conditions, and therefore of their localities. Additionally, we might wonder what the role of global imaginaries is in local actions (Cicchelli and Octobre 2018). At times, a sentiment of belonging to supranational levels accompanies a similar feeling at a national, or even local, level, as is variously discussed throughout the 
chapters. We could assume young people today travel towards adulthood as if they had embodied a cosmopolitan disposition, which we can define, following Hannerz (1990), as containing 'an orientation, a willingness to engage with the Other' (1990: 239). Indeed, young people are often the centre of discourses on cosmopolitism (Farrugia 2020); a cosmopolitan habitus is connected with youthful identities (see also Skrbiš et al 2014). Much recent research discusses assumptions that, for young people, to be 'cool' means being globally connected. However, for a cosmopolitan Bildung to be realised, there must be the acknowledgement that the world is culturally variegated and that the cultures which compose it are not so peripheral or distant (Cicchelli 2012). Further, this global consciousness need not be positively valued. The rise of the young Generation Identity or European Identitarian far-right movements in various European countries can remind us of this, where collectivity is organised against ethnic and cultural pluralism (Ebner 2020). Meanwhile, the appeal of global Islamism mobilised by tech-savvy movements such as ISIS - who have been expert at interpellating a certain disaffected youth demographic also sounds a warning against assuming too much about how the local and global will interact for young people seeking out virtual and real forms of collectivity. We can say, at a minimum, that the experience of locality intersects with broader global processes of social change and continuity (Cuervo and Wyn 2012, Sørensen and Pless 2017, Woodman and Wyn 2015: 60). A cosmopolitan habitus, though, has consequences on local aspirations (Allen and Hollingworth 2013: 508). This attention is also intended to unfold class-based 'habitus' and dispositions towards the educational system, labour markets and family structure, which contribute to broader 'opportunity structures' (Roberts 2009). The editorial project of Brill comprising the book series that hosts this volume, as well two new outlets - a journal called Youth and Globalization and a reference series called Brill Research Perspectives in Global Youth ${ }^{2}$ - is not only a sign of an increased interest in young people's lives in a global perspective but also constitutes a fitting arena to hold such a discussion.

\section{3}

\section{A Theory Roadmap}

We have structured the collection around four dimensions that will guide us in looking at forms of collective engagement. The structure is thematic and

2 "Global Youth Studies" suite, edited by Vincenzo Cicchelli and Sylvie Octobre: http://www2. brill.com/gys. 
develops the following conceptual nodes: forms of collective engagements in (un)employment, (lack of) work, collaborative practices (Part 1); forms of collective engagements in public space (Part 2); forms of collective engagement in forging youth identities through social media (Part 3); forms of youth collectivities in reshaping subjectivities (Part 4). We conclude the collection with an afterword by Carles Feixa.

As an introduction to the chapters that follow, we elaborate some theoretical considerations that take us beyond their global empirical forms. Working inductively on the chapters, in this section, we sketch different perspectives that could offer a tentative theory roadmap, helping researchers in youth studies to further reflect on 'collectivity'. We see - and discuss here - four conceptual dimensions:
a. Collective engagement as solidarity
b. Collective engagement as sociality
c. Collective engagement as assemblage
d. Collective engagement as mediating between structure and agency.

\subsection{Forms of Collective Engagement as Solidarity}

Several chapters in this collection understand collectivity in terms of solidarity. In recent work, Lahusen and Grasso have defined 'solidarity groups' in European contexts as 'informal cliques, formal organizations, or full-fledged nation-states, $[\ldots]$ based on the idea that membership is tied to the expectations of mutual support, even if these expectations might range from informal to formalized, from voluntary to binding rights and obligations' (2018: 5). Solidarity, to mention one dimension, is more than ever tied to the relationship between generations. According to Woodman, 'young people may be living different lives to their parents and even the generation immediately preceding them, and this will change the relationship between generations, in ways that may not be easy to partition into generational conflict, or class-based solidarity' (2020: 7). Therefore, interesting new intergenerational solidarities are on their way. In this book, this collective 'glue' is linked to strategies of survival. Colombo and Rebughini's chapter (Ch. 12) is paradigmatic on this. The authors describe how the present economic context - the increasing weight of individualising mechanisms in working life and the precarious situation it creates for young people - also opens possibilities for new forms of solidarity. The overall picture, however, remains equivocal. If the individuals 'fall' for the individualising jargon of the late-modern 'entrepreneurial' job market, instead of seeing the structural and ideological mechanisms that drive this process, they are indeed less prone to seek collective links. 
On the one hand, 'individualism' may be the shared default condition within the late-modern labour market, a new context familiar to an increasing number of young people in western societies. On the other, it is likewise a discourse that seeks to cover over this collective component and 'subjectify' the individual - tie her to her destiny, make her responsible for that destiny, drive her to compete with other individuals in every aspect of social life. Colombo and Rebughini investigate how individualism in this sense can be collectively fought by being placed at the centre of a consciousnessraising politics that creates political solidarity and collective experience and engagement. The politically engaged informants interviewed by the authors emphasise how solidarity must be learned in collective processes, and they highlight political goals and ambitions which can only be achieved in concert. However, they also talk about their sheer enjoyment of collective intensities and emotions. In this view, seeking and expressing solidarity does not preclude instrumental attitudes - collectivity and individualism are not necessarily opposed.

Colombo and Rebughini are not alone in their interest in the individualisation dynamics affecting the current job market and the difficulties it poses to earlier forms of solidarity building. The contribution by Simms and Adam (Ch. 4) focuses on the diverse responses made by the traditional unions to these new challenges. We are here dealing again with new forms of 'precarious solidarities', yet they place the accent on the situation that results from the increasing 'financialisation' that haunts the late-modern labour market. This creates new demands on traditional unions and limits the relevance of the usual templates of top-down representational union work and organisation. As the authors show, the unions need to appreciate that contemporary solidarities can only be 'organic'; that instead of merely 'uniting' individuals 'mechanically' under a 'common interest', more fragile types of solidarity must be promoted which emerge from below and which recognise the diverse circumstances characteristic for contemporary work. Such union organising must promote new forms of self-organisation, which may then later be canalised into a more formal structure - or maybe not.

The investigation by Andretta and Bracciale (Ch. 8) looks at political engagement among youth against the background of increasing precariousness and transition difficulties. Italy has a high rate of so-called NEET s (youth 'neither in employment nor in education or training'), and the authors quantitatively analyse the political engagement of this group. However, again, the all-toogrim prophesies regarding this group's degree of political participation must be decisively rethought. Above all, an understanding of contemporary forms of social engagement must consider social media's effects. 
Andretta and Bracciale break down political engagement in three variables: talking about politics, conventional protest and online participation. By distinguishing between these areas, a complex picture emerges. Not only do the authors show that it is anachronistic in a late-modern 'mediated' society to focus on customary forms of political mobilisation, but the NEET s, even if less engaged than their peers, protest and participate online significantly more than older Italians. This poses interesting questions as to the effects of social media on political and online engagement. Such findings suggest we must reframe our very understanding of collective political engagement. Further, it underlines that political sociology has much to offer studies of youth transitions in contemporary societies.

\subsection{Forms of Collective Engagement as Sociality}

Other chapters tackle the question of collectivity more directly. Here we are dealing with non-instrumental and more hedonistic forms of collectivity. This is not only about the sheer desire 'to be together' and to cultivate and enjoy collective sentiments for their own sake. In contrast to the researchers above, Carbajo, Martínez and Tejerina (Ch. 5) investigate a less politicised and more leisurely collective space: the Basque concept of the lonja as a meeting place for young adults. These rented places - mostly vacant retail venues - function as informal youth clubs; managed by self-organised groups of friends. The authors consider how the lonja works as the 'genius loci' of a group (Maffesoli 1996) seated between the public and the private. Running and organising the lonja empowers young people through collective engagement and action, selforganisation and self-assigned responsibilities. Here, autonomy from adult supervision goes with enjoying taking part in the collective; seeking the company of peers, with whom they share responsibilities, experiences and affectivities; testing types of collectively generated autonomy. However, even if apolitical by most conventional understandings, the collective learning processes occurring in the lonjas may very well be political in a broader sense. These spaces do not fit the usual top-down schemas of commercialised youth consumption. Further, the young people in these collectives complement or even challenge the general concept of political agency - namely, by sharing economic expenses in times of precariousness and by self-organising and claiming their autonomy outside the sphere of adult control and of traditional forms of political organisation.

We find the same direct engagement in collectivity in the chapter by Cuzzocrea, Krzaklewska and Cairns (Ch. 7). The three authors investigate the collective dimensions in Erasmus exchange students' experiences. The Erasmus groups' international conviviality, which emerges more out of the 
willingness to encounter one another than engaging with the local culture of the host institution or city, leads to creating what people often refer to as a social 'bubble'. The incoming students often form no ties to the local students, who have their relations in place and lack motives for investing emotionally and socially in the transient Erasmus students. As such, the Erasmus students are often left to socialise among themselves. Add to this that the Erasmus cohort shares a situation of institutional and existential insecurity - many are away from home for the first time and thus suddenly liberated from adult supervision and constraining role expectations and identities. Quickly formed intimacies and intense collective engagement result from this shared position. The Erasmus period's transience further inflates this 'bubble', creating a strong sense of shared presence alongside the desire to enjoy further and explore the collective while it lasts. In all, this lends the period an intensity underlined by its time horizon. More, these sentiments should not be (mis)understood as superficial. As the authors also show, the intense energies inside the Erasmus bubble create friendships and networks which last for years after the Erasmus period. To speak with Durkheim, if they pay regular visits to one another, hold reunions and cultivate contacts, they can keep the collective energies alive after the original 'gathering'.

Waechter (Ch. 9) investigates collective experience in a concrete and non-purposive vein. She writes about teenagers' use of social media and the nature of the collectivities unfolding online. The chapter is concerned with the collective dimension of social media use in two gendered online environments: Instagram (girls) and multiplayer computer games (boys). Both groups enter an online community of peers seeking reactions, 'likes', conviviality and intimacy. As Waechter emphasises, even if this is also a space for hate speech and bullying (boys) or for constraining forms of bodily aestheticization and sexualisation (girls) - creating insecurity and self-esteem problems - this picture needs to be complemented by a positive and collectivist one. The girls reinforce offline group belonging and existing social ties by uploading group or 'best friends' photos, commenting affirmatively on each other's actions, and collectively exploiting and intensifying creative practices of stylisation and self-expression. The boys dig directly into collective energies unfolding with the game through direct audio and video communication, enforcing team sentiments and intensities when they play against other teams. Without losing critical distance, Waechter shows the utter importance of the collective dimension in young lives. In fact, it animates everything these young people do on these social platforms.

Juchniewicz and Grabowska (Ch. 10) analyse the forms and meanings of social media use in the lives of young migrants. After delivering a theoretical 
overview of the collectivist side to social media use in migratory lives, they investigate the role of what they term assisting collectivities. Social media facilitates and cultivates these relations. Their functions and compositions are diverse and selective. The term 'assisting collectivities' thus covers both strong ties to family and friends, and weak ones to more distant or anonymous career models and influencers. Assisting collectivities help with emotional encouragement and practical support both before, during and after migration; they include latent networks or ties at the destination; they provide inspiration and information for migratory career planning and decision-making. The authors describe how the young plug into but also unplug from these collectivities; how they shift between different groups, using them selectively - according to different challenges, activities and stages in the migratory process. As the authors aptly show, collectivity is also a resource. The exact balance between nonstrategic and non-purposive processes of mere 'being together' and conscious and instrumental exploitation of 'social capital' is often irrevocably blurred.

\subsection{Forms of Collective Engagement as Assemblage}

Another set of chapters places a Deleuzean concept of collectivity at the centre of their investigations. Conceptualising societal forms as assemblage is by no means standard in youth research. Some recent work has gone in this direction (for instance, Kamp and Kelly and Nilan in a collection edited by Kamp and Kelly in 2015; Filho and Kamp 2019). This collection further develops such an approach - and we, therefore, take the occasion to offer some reflection on its usefulness.

Given that many youth researchers may be unfamiliar with the terminology and concepts at play in this approach, a short genealogical detour is worth taking. The somewhat technical-sounding English term assemblage comes across from the French agencement, which more literally means arrangement. In French, it has connotations of arranging, organising and fitting together - and putting into action (Livesey 2010: 18-19). In this sense, it mirrors the various connotations of 'assembly' in English, be they 'assembling' a piece of furniture or an 'assembly' of all a school's students in one place. Following the French theorists, assemblages are thus a rich constellation of objects, bodies, expressions, qualities and territories. They may come together to create novel forms of functioning among these elements - but they will only remain stable for a limited time. In other words, these transient arrangements transpire when a set of forces coalesces. Put differently again, the assemblage arranges a set of heterogeneous elements into a network. From this may emerge a new institution, a new means of expression, a new set of behaviours or, indeed, a new experience of reality. The assemblage connects its components in various ways 
and is often surprising in what it connects - yet it may continue certain relations of power. Nilan shows the relevance for scholars in this field: 'Deleuze and Guattari's notion of assemblage captures a process of constant becoming in which many youth culture elements are (re)assembled and interact to form a non-centred multiplicity. Since the young people in an assemblage are 'becoming' through continuous transformation; as new relations are brought into play, new assemblages of youth culture emerge' (Nilan 2015: 270).

Raby and Lehmann (Ch. 3) take this approach and challenge the standard conception of adult independence and autonomy present in much youth research. In contrast to this standard view, a proliferation of (new) attachments and relations generate autonomy. Extending the concept of the collective to our non-human relations, a growth in collectivity becomes synonymous with growth in individuality. Here, the concept of individuality becomes ideological in the sense that it covers over its social constitution, not merely in the sense that it emerges in a modern societal 'context' marked by the division of labour, ever-growing mobility and disappearance of ascriptive categories, but in the sense that its concrete exercise is rooted in material and immaterial 'supplementations' and 'extensions'. Following Deleuze, we are all assemblages without clear borders and entangled in other assemblages.

On this theoretical base, the authors construct a 'teen-work' assemblage. It comprises multiple elements: technology at the workplace, transport infrastructure, relations to other humans or other bodies (family and friends, helping at work or getting jobs), languages and belief systems (about growing up, having one's first job), the money earned, moral convictions (to save the money in responsible ways or to spend as an independent 'adult' consumer). All these relations make it possible for the young working person to feel responsible and autonomous; to 'grow up' and become an adult. However, as Raby and Lehmann also demonstrate, such concepts of collectivity do not exclude structural awareness or critical interest in privilege; it is possible to work through all these elements focusing on their inherent inequalities (e.g., who depends on public transport, who has native-speaker parents at home).

Mansfield also takes her point of departure from assemblage theory. In her chapter (Ch. 6) on Indonesian graffiti culture and forms of 'collective individuality', she investigates less 'individualist' forms of individuality than those typically found in the western narrative of transition. As she points out, the western model does not entirely fit the modes of collectivity in places such as Indonesia. Mansfield thus moves on to show how the Indonesian 'graffiti assemblage' comprises all kinds of human and non-human elements. We are dealing with city walls; spray cans; paint shops; new colours; emerging graffiti pieces or characters; human relations and inspirations, local and global 
(through concrete interaction or social media); liberal Indonesian graffiti policies; relations to the surrounding community; traditions and traditional gender roles - and various other elements. These assemblages mediate between individuality and sociality, or better still, they produce forms of individuality that are inherently social, shaped through concrete attachments and entanglements.

On the one hand, the individualities of the young are inseparable from their signature graffiti pieces, their 'styles' and personal expressions called forth by the material work at hand. On the other, their individuality is embedded in and animated by collective experiences and engagement with fellow practitioners and friends, with the broader Indonesian community, and with graffiti idols and models accessible through social media. Mansfield shows how collective intensities permeate such groups. Deleuze and Guattari, it is worth remembering, describe how desire is the energy in the assemblage that circulates to produce connections.

Mansfield is drawn to the meaning and significance of this latter dimension. Here the reader encounters new forms of non-productive and noninstrumental, decentred and self-organising practices of being together. These practices decisively contribute to stabilising the assemblage and further energising its (other) elements. The collective Indonesian practice of nongkrong stands at the centre of Mansfield's analysis. Instead of seeing this as a form of merely 'doing nothing', as analysed long ago by the Birmingham subcultural scholars, the Indonesian traditions permit real cultivation of this nonpurposive form of collectivising.

\subsection{Forms of Collective Engagement as Mediating between Structure and Agency}

Other contributions are more traditional in their theoretical outlook-informed by the conventional dichotomy between actor and structure, individual biography and historical and societal context. This is perhaps the longest-running methodological and conceptual tension in the social sciences. We will not recapitulate that debate here. We merely wish to remark that this opposition individualises the social or at least hides concrete collective ties behind a more abstract notion of the social facing the individual: a structure of norms, a 'societal' context or typical gendered or classed vocational aspirations.

However, the contributions to this book, taking departing from this distinction, seek to describe the concrete - and irredeemably collective - 'place' of transmission, socialisation or mediation. This is the case with the contribution from Nilsen and Vogt (Ch. 11). They investigate from inside the family, as it were, how structure is encapsulated in 'taken for granted' ideas and aspirations 
and thus transmitted among concrete persons and relations. In very recent debates, the discussion on the 'taken for granted' has stretched into investigating, inter alia, intergenerational transfers (Woodman 2020, Cook 2020) as an add-on to resources available to youth. Within this collection, this chapter valuably brings to the fore some classic concepts in sociology, and helps us reconsider how they can be revisited when the focus is more directly centred on forms of collectivity. The collective emerges here in the scene of class and family, whereby the taken-for-granted becomes a means to investigate this scene anew.

Other contributors share these theoretical orientations. Schlimbach and Reißig (Ch.2) highlight similar dynamics, yet in an even more concretesense, also due to the longitudinal approach used. Given the increased insecurity and anxiety that marks the late-modern period, they show the crucial role of peers and networks as reference points for educational and vocational orientation, and sources of emotional comfort and support. They not only fill a research gap in transition research by using a pedagogical background, but they also invite a more concrete concept of the social inside the structural-individual framework. The concept of 'arenas of comfort' used here, initially formulated by Simmons et al in 1987 , helps to illustrate the mediation between structure and agency within a realm distinct from Nilsen and Vogt's chapter, given that it pertains to an educational setting. In doing so, it allows us to see collectivity unfolding horizontally rather than vertically as in the previous chapter, establishing the basis for a redefinition of the more widespread concept of socialisation. On this basis, the contributions assembled here correct, or at least complement, transition research's usual image of a friendless or relationless transitioning individual - placed in a context or a structure, but always lonely - and do so while concurrently focusing on key actors around the transition to adulthood experience.

\section{4}

\section{Conclusions}

Returning to the transport metaphor launched in the youth transition debate by Furlong and Cartmel in 1997, we need to consider how young people travel towards adulthood within the communities with whom they interact. In this collection, we propose that whatever means of transport they take, it will be with others that young people build their transition, and therefore only with other people, rather than alone, will they be able to construct their path in uncertain socio-economic terrain. For, as we discuss here, these collectivities take diverse forms from the most institutionalised to most informal. While 
collective engagements may have political implications, which are investigated more broadly in movement studies, we believe it is useful per se to rethink forms of collectivity in their potential to facilitate youth transitions.

We remain strongly sympathetic to a youth studies approach that pushes for structural changes to help smooth out these transitions (for instance, through policies). We are also confident that young people will do their part to identify means of transport which are both smart and better correspond to their taste: for instance, bikes, electric bikes or scooters which they may use individually, but perhaps are chosen too because of a collective project (for instance, to reduce environmental impact). The global spread of the Fridays for Future movement, for instance, which has sprung up and flourished as we prepare this book for print, indicates a youth sensibility towards collective responsibility, in a way that, for now, is both generationally articulated and superseding the concerns of previous generations. Alternatively, as in the very final days before we go to print, a resurgent and global Black Lives Matter movement instigated by the police murder of George Floyd in the US, coming together even as physical distancing measures have been in place to halt the spread of the covid 19 pandemic. We, therefore, advocate creative and open reading of forms of collective engagement to maximise their heuristic potential, particularly at a time of novel protest and coalitions.

Further, the four regions of theoretical development in the book have put into question the treatment of issues such as solidarity, sociality, assemblage and mediation between structure and agency. While these have received much attention in the social sciences and humanities, they remain relatively little discussed in youth research as pertinent to the core concerns of the field. The agency and structure debate, conversely, is well established - but, we argue, in a way that easily supersedes any collective dimension. Our overview wishes to induce further reflection. We have grouped contributions according to the theoretical insights they have developed, intimating how future youth research can generalise and extend these paradigms.

In closing, we acknowledge some strengths and limits of our focus. First, collective engagement is not unambiguously virtuous. Gender issues, in particular, can go unnoticed in new forms of collective engagements, as shown by Waechter in her analysis of social media. The chapter by Carbajo et al stresses how the lonjas underwrite gender asymmetries and stereotypes. They are not, then, necessarily positive forms of aggregations. Similarly, the Erasmus bubble has downsides (Ch. 7), in the internal functioning and its development and transformation over time, as well as concerning what exists outside of it. Above all, the manifest limitation is the lack of a link and social bonds between Erasmus students and local students or other locals. So, this is our warning: 
it is not enough to congregate together to smooth these transitions, nor will that immediately translate into emancipatory practices. A strong tradition of youth research understandably wants to present youth as capable of navigating and creating new forms of sociability, activity and opportunity in harsh conditions. Whatever the precise socio-political commitments that undergird such a research position, we cannot avoid recent developments of youth collectivities that appear to go in some alarming directions - such as the altright, particularly in the US, and 'identitarian' movement within the EU. While some policy devices recognising spaces to youth have been experimented with (Cuzzocrea and Collins 2015, 2020), we wish to underline an alarming coalescence of youth disaffection, socio-economic conditions, challenges to identities of those previously culturally hegemonic (e.g. white, male, straight) and all linked via social media platforms. Youth can be uncritically lauded as a progressive force - even if history repeatedly shows this being a misnomer. Thus, the set of collective engagements we see today ought to once again give us pause and push our concepts to grapple with new empirical phenomena in their diversity.

An additional possibility for expanding discussions about youth collectivities, beyond the empirical 'themes' and theoretical paradigms we have analysed and gathered here, would go in the direction of recognising more directly the contributions of (youth) subculture research to transition research. This is in line with suggestions in the past decade from Woodman and Bennett (2011) and Furlong et al (2011), among others. If youth (sub)cultures can be defined by the ways 'young people's social experiences are expressed collectively through the construction of differentiating lifestyles, mainly in leisure time, or in interstitial spaces in the institutional life' (as in Feixa and Nofre 2012: 1), then once we establish that those interstitial areas are apt for varieties of collectivities to emerge among young people, as it seems possible to say about all forms of collective engagement discussed in this book, it becomes imperative not only to broaden the space in which transitions to adulthood happens, and therefore to redefine youth transitions research - but also to establish youth collectivity as a heuristic with the potential to help this shift happen. In this sense, these two strands of youth research converging becomes crucial for studying youth. With this collection, we invite others to explore further all the overlaps and possible new directions from here. We do not see the book as the task's completion - but a building site where other labourers with other expertise may join in. We hope that people around the globe take up this invitation, seeking to add 'collectivity' to the active vocabulary of youth studies. 


\section{References}

Abbott Andrew. 2001. On the concept of turning point, in Time Matters: On Theory and Method. Chicago: University of Chicago Press, pp. 240-26o.

Allen Kim, and Hollingworth Sumi. 2013. 'Sticky Subjects' or 'Cosmopolitan Creatives'? Social Class. Place and Urban Young People's Aspirations for Work in the Knowledge Economy, Urban Studies 50: 499-517.

Bagnoli Anna and Ketokivi Kaisa. 2009. At a crossroads. Contemporary lives between fate and choice, European Societies 11(3): 315-324.

Bauman Zygmunt. 2001. The individualised society. Cambridge: Polity.

Beck Ulrich and Beck-Gernsheim E. 2002. Individualization. London: Sage.

Beck Ulrich. 1992. Risk Society. Towards a New Modernity. London: Sage.

Bertolini Sonia, Moiso Valentina and Unt Marge. 2019. Precarious and creative: youth facing uncertainty in the labour market, in Youth and the politics of the present: Coping with Complexity and Ambivalence, in Colombo Enzo and Rebughini Paola (eds), London: Routledge, pp. 75-87.

Biggart Andy and Walther Andreas. 20o6. 'Coping with Yo-Yo-Transitions: Young Adults' Struggle for Support, between Family and State in Comparative Perspective', in Leccardi Carmen and Ruspini Elisabetta (eds) A New Youth? Young People, Generations and Family Life, Farnham: Ashgate, pp. 41-62.

Bynner John, Elias Peter, McKnight Abigail, Pan Huiqi and Pierre Gaëlle. 2002. Changing Pathways to Employment and Independence. York: YPs for the Joseph Rowntree Foundation.

Brannen Julia and Nilsen Ann. 2005. Individualisation, choice and structure: a discussion of current trends in sociological analysis, Sociological Review: 412-429.

Brannen Julia and Nilsen Ann. 2002. Young people's Time perspectives: from Youth to Adulthood, Sociology 36(3): 513-537.

Cicchelli Vincenzo and Octobre Sylvie. 2018. Aesthetico-Cultural Cosmopolitanism and French Youth: The Taste of the World, London: Palgrave.

Cicchelli, Vincenzo. 2012. The Cosmopolitan 'Bildung' of Erasmus Students' Going Abroad. In Critical Perspectives on International Education, edited by Y. Hébert and A. et Abdi, Rotterdam/Taipei: Sense Publishers, pp. 205-208.

Cook Julia. 2020. 'Keeping it in the family: understanding the negotiation of intergenerational transfers for entry into homeownership', Housing Studies, DOI: 10.1080/ o2673037.2020.1754347.

Colombo Enzo and Rebughini Paola. 2019. A complex uncertainty: young people in the riddle of the present, in Colombo Enzo and Rebughini Paola (eds). 2019. Youth and the politics of the present: Coping with Complexity and Ambivalence, London: Routledge, pp.1-16. 
Colombo Enzo, Leonini Luisa and Rebughini Paola. 2018. A generational attitude: Young adults facing the Economic Crisis in Milan, Journal of Modern Italian Studies 23(1): 61-74.

Cuzzocrea Valentina and Collins Rebecca. 2015. 'Collaborative individualization?' Peer-to-peer action in youth transitions, Young 23(2): 132-53.

Cuzzocrea Valentina and Collins Rebecca. 2020. Youth transitions as 'wiki-transitions' in youth policies platforms, European Societies 22(4): 411-432.

Côté, James. E. 2002. The role of identity capital in the transition to adulthood: the Individualization book examined, Journal of Youth Studies 5(2): 117-143.

Cuervo Hernán and Wyn Johanna. 2012. Young people making it work: Continuity and change in rural places. Melbourne: Melbourne University Publishing.

Deleuze Gil and Félix Guattari.1987. A ThousandPlateaus. Capitalism and Schizophrenia. Minneapolis: University of Minnesota Press.

Ebner Julia. 2020. Going Dark: The Secret Lives of Extremists. London: Bloomsbury.

Farrugia David. 2020. Class, place and mobility beyond the global city: stigmatisation and the cosmopolitanisation of the local, Journal of Youth Studies 23(2): 237-251.

Feixa Carles and Nofre Jordi. 2012. 'Youth cultures', Sociopedia.isa. http://www.sagepub. net/isa/resources/pdf/YouthCultures.pdf.

Filho Alfredo Salomão and Kamp Annelies. 2019. Performing mundane materiality: Actor-Network Theory, global student mobility and a re/formation of 'social capital', Discourse: Studies in the Cultural Politics of Education 4O(1): 122-135.

Foster Karen Rebecca, Spencer Dale. 2011. At risk of what? Possibilities over probabilities in the study of young lives, Journal of Youth Studies 14(1): 125-143.

France Alan and Roberts Steven. 2017. Youth and social Class: enduring inequality in the United Kingdom, Australia and New Zealand, Springer.

Furlong Andy and Cartmel Fred. 2007, orig. ed. 1997. Young People and Social Change: New Perspectives. Maidenhead: Open University Press.

Furlong Andy and Kelly Peter. 2005. The Brazilianisation of youth transitions in Australia and the UK?, Australian journal of social issues 4O(2): 207-225.

Furlong Andy, Woodman Dan and Wyn Johanna. 2011. Changing times, changing perspectives: Reconciling 'transition' and 'cultural' perspectives on youth and young adulthood, Journal of Sociology 47(4): 355-370.

Hannerz Ulf. 1990. Cosmopolitans and Locals in World Culture, Theory, Culture, and Society $7(2-3): 237-5^{2}$.

Holdsworth Clare. 2013. Family and Intimate Mobilities. Basingstoke: Palgrave Macmillan.

Howie Luke and Campbell Perri. 2017. Crisis and Terror in the Age of Anxiety: 9/11, the Global Financial Crisis and ISIS, London: Palgrave Macmillan.

Jones Gill. 2002. The Youth Divide. Diverging paths to Adulthood, York Publishing Services for the Joseph Rowntree. 
Kamp Annelies and Kelly Peter. 2015. On Assemblage, in Kelly Peter and Kamp Annelies A critical youth studies for the 21st century, Leiden: Brill, pp. 242-249.

Kamp Annelies. 2015. Deleuze and the Teenage Mother. Trouble Makers for Education and Transition, in Kelly Peter and Kamp Annelies (eds), A critical youth studies for the 21st century, Leiden: Brill, pp. 123-140.

Kelly Peter and Kamp Annelies (eds). 2015. A critical youth studies for the 21st century. Leiden: Brill.

Lahusen Christian and Maria Grasso. 2018. Solidarity in Europe-European Solidarity:An Introduction, in C. Lahusen, M. Grasso (eds.), Solidarity in Europe, London: Palgrave.

Leccardi Carmen. 20o9. Sociologie del Tempo. Roma-Bari: Laterza.

Livesey Graham. 2010. 'Assemblage' in The Deleuze Dictionary: Revised Edition, Edinburgh: Edinburgh University Press.

Lyon Dawn and Crow Graham. 2012. The challenges and opportunities of re-studying community on Sheppey: Young people's imagined futures. Sociological Review 6o: $498-517$.

Maffesoli Michel. 1996. The Times of the tribes. The Decline of individualism in mass society. Sage: London.

Magaraggia Sveva and Benasso Sebastiano. 2019. In Transition ... Where to? Rethinking Life Stages and Intergenerational Relations of Italian Youth. Societies 9(1):1-15.

McDonald Paula, Grant-Smith Deanna, Moore Katherine and Marston Greg. 2020. Navigating Employability from the Bottom Up. Journal of Youth Studies 23(4): 447-464.

Mead George Herbert. 1934. Mind, Self and Society: From the Standpoint of a Social Behaviorist, Chicago: University of Chicago Press.

Mills C. Wright. 1939. Language, logic, and culture. American Sociological Review 4(5): $670-8$ o.

Mills C. Wright. 1959. The Sociological Imagination, New York: Oxford University Press.

Mørch Sven and Andersen Helle. 2006. Individualisation and the changing youth life in: Leccardi Carmen and Ruspini Elisabetta (eds.), A new youth? Young people, generations and family life, Cambridge: Ashgate: 63-84.

Nilan Pam. 2015. Youth Culture in/beyond Indonesia. Hybridity or Assemblage? In Kelly Peter and Kamp Annelies (eds), A critical youth studies for the 21st century, Leiden: Brill, pp. 242-249.

Nilsen Ann. 2021. Independence and relationality in notions of adulthood across generations, gender and social class. The Sociological Review 69(1): 123-138.

Nilsen Ann and Brannen Julia. 2014. An Intergenerational Approach to Transitions to Adulthood: The Importance of History and Biography. Sociological Research Online 19(2): 1-10.

Roberts Ken. 2009. Opportunity structures then and now. Journal of education and work 22(5): $355^{-368 .}$ 
Roberts Steven. 2010. Misrepresenting 'choice biographies'?: A reply to Woodman. Journal of Youth Studies 13(1): 137-149.

Roberts Steven. 2012. One step forward, one step Beck: A contribution to the ongoing conceptual debate in youth studies. Journal of Youth Studies 15(3):389-401.

Roberts Steven and France Alan. 2021. Problematizing a popular panacea: A critical examination of the (continued) use of 'social generations' in youth sociology. The Sociological Review 69(4): 775-791, DOI: 10.1177/oo38026120922467.

Schiermer, Bjørn, Ben Gook and Valentina Cuzzocrea (eds), Youth Collectivities: Objects and Cultures, in press, London: Routledge.

Skrbiš, Zlatko, Ian Woodward, and Clive Bean. 2014. Seeds of Cosmopolitan Future? Young People and their Aspirations for Future Mobility, Journal of Youth Studies 17(5): 614-625.

Simmons, Roberta G., Richard Burgeson, Steven Carlton-Ford, and Dale A. Blyth. 1987. The Impact of Cumulative Change in Early Adolescence. Child Development $58(5): 1220$.

Sørensen Niels Ulrik and Pless Mette. 2017. Living on the periphery of Youth: young people's narratives of youth life in rural areas, Young $25(4 \mathrm{~S}): 1 \mathrm{~S}-17 \mathrm{~S}$.

Spanò Antonella and Markieta Domecka. 2020. Pathways towards adulthood in times of crisis: reflexivity, resources and agency among young Neapolitans, in Italian Youth in an International context, Cuzzocrea, Bello and Kazepov (eds), London: Routledge.

Tejerina Benjamín. 2019. Youth and precariousness in Spain: beyond a waiting time, in Youth and the Politics of the Present. Coping with Complexity and Ambivalence, Colombo Enzo and Rebughini Paola (eds), 88-10o, London: Routledge.

Thomson Rachel, Bell Robert, Holland Jane, Henserson Sheila, Mcgrellis Sheena and Sharpe Sue. 2002. Critical Moments: Choice, Change and Opportunity in Young People's Narratives of Transitions, Sociology 36(2): 335-354.

Threadgold Steven. 2018. Youth, Class and Everyday Struggles, London: Routledge.

Threadgold Steven. 2011. Should I pitch my tent in the middle ground? On 'middling tendency', Beck and inequality in youth sociology, Journal of Youth Studies 14(4): 381-393.

Tomanović Smilijka. 2012. Agency in the Social Biographies of Young People in Belgrade, Journal of Youth Studies 15(5): 605-620.

Woodman Dan. 2009. The mysterious case of the pervasive choice biography: Ulrich Beck, structure/agency, and the middling state of theory in the sociology of youth, Journal of Youth Studies 12(3): 243-256.

Woodman Dan. 2010. Class, individualisation and tracing processes of inequality in a changing world: a reply to Steven Roberts, Journal of Youth Studies 13(6): 737-746.

Woodman Dan. 2020. Generational change and intergenerational relationships in the context of the asset economy, Distinktion: Journal of Social Theory, ifirst, 12 May. 
Woodman Dan and Bennett Andy. 2011. Youth Cultures, Transitions and Generations: Bridging the Gap in Youth Research, London: Routledge.

Woodman Dan and Wyn Johanna. 2015. Youth and Generation. Rethinking change and inequality in the lives of young people, London: Sage.

Wyn Johanna, Cahill Helen, Cuervo Hernán, Chesters Jenny, Cook Julia and Reade Josie. 2017. Gen Y on Gen Y. Youth Research Centre Report. Melbourne Graduate School of Education. 2017 . 
Valentina Cuzzocrea, Ben Gook, and Bjørn Schiermer - 9789004466340 Downloaded from Brill.come4/26/2023 12:26:15PM via free access 